\title{
La CUT y los clivajes sindicales en Chile. Entre la pretensión transformadora y la estrategia defensiva $^{1}$
}

\author{
TThe CUT (Workers' United Center of Chile) and union cleavages in Chile. Between the \\ transforming claim and the defensive strategy
}

RODRIGo M. MEDEL

Universidad Alberto Hurtado, Chile

\begin{abstract}
RESUMEN Este artículo plantea que, desde el retorno a la democracia en Chile, la Central Unitaria de Trabajadores (CUT) ha desempeñado un doble papel para el sindicalismo. Por una parte, ha buscado promover, con muy pocos recursos y poco éxito, una nueva legislación para el sector privado del sindicalismo y; por otro, ha defendido, con muchos recursos y éxito, la autonomía y los intereses del sector público. ¿Cómo ha impactado en las identidades y prácticas organizacionales de los sindicatos chilenos este doble papel jugado por la CUT desde el retorno a la democracia? Para responder esta pregunta, se propone el concepto de clivajes sindicales, el que describe una división que es, simultáneamente, estructural, ideológica y organizativa dentro del sindicalismo chileno. A partir de un análisis histórico, se describe cómo el mismo accionar de la CUT fue politizando la división estructural entre el sector público y el privado del sindicalismo, consolidando identidades colectivas en torno a dicha división. Luego, con un análisis cuantitativo de las redes de alianzas en huelgas laborales desde el 2010 hasta el 2019, se describe el comportamiento diferenciado de las principales federaciones según su pertenencia al sector público o privado. Los resultados muestran que las federaciones del sector público son las que encuentran mayor densidad de alianzas entre ellas, generando un clivaje claramente diferenciado del sindicalismo del sector privado, el que se en-
\end{abstract}

1. Al autor le gustaría agradecer el apoyo de dos proyectos ANID del Ministerio de Ciencia (FONDECYT/1200190, y FONDECYT/1190070). 
cuentra aislado social y políticamente. Se resalta la importancia de considerar esta fractura dentro del sindicalismo chileno como un elemento altamente explicativo de las limitaciones y fortalezas en la capacidad política de la Central.

PALABRAS CLAVES Sindicalismo; clivajes sindicales; centrales sindicales; reformas laborales; alianzas.

ABSTRACT This article states that, since the return to democracy in Chile, the Central Unitaria de Trabajadores (CUT) has played a double role for unionism. On the one hand, it has sought to promote, with very few resources and little success, new legislation for the private sector and, on the other, it has defended, with many resources and much success, the autonomy and interests of the public sector. How has this dual role played by the CUT since the return to democracy impacted on the identities and organizational practices of Chilean unions? To answer this question, it is proposed the concept of union cleavages, which describes a division that is simultaneously structural, ideological and organizational within Chilean unionism. Based on a historical analysis, it is described how the actions of the CUT were politicizing the structural division between the public and private sectors of unionism, consolidating collective identities around that division. By means of a quantitative analysis of the alliance networks in labor strikes from 2010 to 2019, the differentiated behavior of the main federations is described, according to whether they belong to the public or private sector. The results show that the public sector federations are the ones that find the highest density of alliances between them, generating a cleavage that is clearly differentiated from the private sector unionism, which is socially and politically isolated. The importance of considering this fracture within Chilean trade unionism is highlighted as a highly explanatory element of the limitations and strengths of CUT's political capacity.

KEYWORDS Trade unionism; union cleavages; union centrals; labor reforms; alliances.

\section{Introducción}

La dictadura militar chilena dejó múltiples herencias institucionales. La más importante y cuestionada de todas es la constitución política de 1980. Pero antes del texto constitucional, el año 1979, la junta militar promulgó una serie de leyes que instalaron un nuevo modelo de relaciones laborales para el sector privado, conocido como Plan Laboral. 
Luego de más de tres décadas desde el retorno a la democracia en 1990 y más de 200 enmiendas al Código del Trabajo, los pilares del código siguen intactos (Gamonal, 2011). Diversas explicaciones se han dado respecto a la poca influencia que ha tenido la Central Unitaria de Trabajadores (CUT) en la legislación laboral chilena, pero de una u otra manera, todas aluden a la debilidad que tiene el sindicalismo vinculado a la Central. Se trata de un sindicalismo políticamente débil, ya sea por divisiones internas que lo debilitan frente a la contraparte empresarial (Pérez, 2017), por un abandono de sus pretensiones transformadoras (Ulloa, 2003) o por una separación respecto a sus bases que dificultan la movilización (Osorio \& Gauichaud, 2015).

Sin embargo, hay que matizar el argumento respecto a la debilidad sindical generalizada de la CUT, por cuanto la Central no sólo ha cosechado derrotas desde el retorno a la democracia. Su principal victoria, es que ha logrado fortalecer su alianza e incidencia con los sectores que se mueven por fuera del Plan Laboral y que buscan mantener esa autonomía, principalmente el sector público. Ejemplo de ello, es que tanto en las multitudinarias huelgas impulsadas por el Colegio de Profesores (Álvarez, 2019), como en todas las negociaciones ramales por el reajuste salarial del sector público, que hasta 1995 alcanzaron a ser mayores al 10\% (Quiroga, Guerrero \& Schuster, 2016), la CUT ha jugado un rol fundamental.

Es así como la CUT ha desempeñado un doble papel para el sindicalismo desde el retorno a la democracia; por una parte, ha buscado promover, con muy pocos recursos y poco éxito, una nueva legislación para el sector privado del sindicalismo y; por otro, ha defendido, con muchos recursos y éxito, la autonomía y los intereses del sector público. ¿Cómo ha impactado en las identidades y prácticas organizacionales de los sindicatos chilenos este doble papel jugado por la CUT desde el retorno a la democracia?

El argumento de este artículo es que la principal consecuencia que ha tenido la política de la CUT ha sido la conformación de dos clivajes sindicales: el sindicalismo del sector público y el sindicalismo del sector privado.

El concepto de clivajes se ha utilizado tradicionalmente para estudiar divisiones sociales que son politizadas, y en base a los cuales se organizan los partidos (Lipset y Rokkan, 1967).

Sin embargo, su aplicación puede ir más allá del comportamiento electoral partidista. De acuerdo con Bartolini y Mair (2007), la peculiaridad del concepto de clivaje es su capacidad de unir lo social con lo ideológico y con las divisiones conductuales/ organizacionales (Bartolini y Mair, 2007). Por ello, para hablar de clivajes debe haber una división estructural en la sociedad, debe haber consciencia de esa división expresada en una identidad colectiva, y finalmente debe existir un componente organizativo que politice dicha división. 
En este artículo se busca describir cómo el mismo accionar de la CUT fue politizando la división estructural entre el sector público y el privado del sindicalismo, consolidando identidades colectivas en torno a dicha división y generando alianzas diferenciadas entre las principales federaciones y la CUT.

En los siguientes dos puntos del artículo, se repasa brevemente la historia de la CUT desde el retorno a la democracia, pasando por el giro sociopolítico de mediados de los 2000, hasta la reforma de Bachelet. Luego, en el punto cuatro, se describe como esta división público- privada en el sindicalismo va articulando una ideología diferenciada, para lo cual se ofrece evidencia de literatura secundaria y de trabajos cualitativos previos realizados por el autor. En el punto cinco se realiza un análisis cuantitativo de las redes de alianzas en huelgas laborales desde el 2010 hasta el 2019, utilizando la base de datos del Observatorio de Huelgas Laborales (OHL). Para ofrecer evidencia de que existe un comportamiento organizativo diferenciado dentro del sindicalismo en Chile determinado por los clivajes público-privado, se trabaja con una serie de indicadores de alianzas entre las federaciones y confederaciones. Los resultados del análisis de redes descriptivo muestran que las huelgas de federaciones del sector privado se encuentran aisladas social y políticamente; mientras que las huelgas de federaciones del sector público expresan fuertes alianzas entre ellas y con la CUT. Finalmente se discuten las consecuencias que estas divisiones tienen y los posibles caminos del sindicalismo frente a las coyunturas recientes.

\section{La CUT, los partidos y la transición a la democracia}

El sindicalismo chileno se encuentra actualmente dividido en cuanto a su relación con las centrales sindicales. Sin embargo, eso no ha sido siempre así. El nacimiento de los clivajes sindicales en Chile fue un proceso paulatino, cuyo origen se remonta a los primeros gobiernos post transición, a partir de cuando se comienza a abrir una fractura paulatina dentro del movimiento laboral vinculado a la Central. El discurso de la transición de la CUT se basó en recrear lo que era el período anterior al golpe de Estado en 1973, donde los partidos políticos tenían un rol protagónico dentro del sindicalismo. En ese sentido, la CUT buscó ser una extensión de los partidos de la Concertación (Frank, 2004; Winn, 2004).

Dicho intento de complementariedad encontró rápida respuesta desde los partidos. Ante un estadio nacional lleno, el 12 de marzo de 1990, Patricio Aylwin incluyó en el discurso de inauguración de su presidencia una instrucción al Ministro de Hacienda, de Trabajo y Economía, "para que instalaran inmediatamente una mesa de diálogo con la Central Unitaria de Trabajadores" (Foxley y Sandoval, 1999, p. 69).

En este contexto fue que el presidente de la recién recuperada democracia promovió el "Acuerdo marco nacional tripartito", entre empresarios, trabajadores y el gobierno. Pese a las reticencias de los sectores de izquierda dentro de la CUT, el li- 
derazgo concertacionista de la central motivó la firma del Acuerdo Marco de abril de 1990 (Osorio, 2015). Se trataba de un acuerdo históricamente novedoso en Chile, por cuanto suponía un encuentro inédito entre los dos grandes actores adversarios del período previo a la dictadura: trabajadores y empresarios.

Diversos estudiosos del sindicalismo chileno han centrado su atención en las implicancias de la firma de estos "Acuerdos Marco", como un momento altamente explicativo sobre el devenir de la CUT los años venideros. Para González y Zapata, estos acuerdos marcaron el inicio de una falta de autonomía de la CUT respecto a los partidos, lo que ha definido una imposibilidad de presionar desde las bases por un sistema de relaciones laborales más equilibrado entre trabajadores y empresarios (González y Zapata, 2016).

Otros autores señalan que el "Acuerdo Marco" fue fundamental para definir el período, puesto que daría legitimidad a políticas orientadas a superar los disensos sobre el orden sociopolítico y económico e instalaría "de hecho" el modelo neoliberal en su vertiente laboral como la ruta que seguiría el país de ese entonces hacia adelante (ver, por ejemplo, Campero, 2007; Frías, 2008).

Pero también sería injusto decir que la CUT simplemente adoptó el modelo laboral de la dictadura. Por el contrario, desde el nacimiento de la Central Unitaria de Trabajadores (CUT) en agosto de 1988 hasta la actualidad, el objetivo programático cardinal de la multisindical ha sido la derogación del código laboral ideado en dictadura. Muestra de aquello se encuentra en la Declaración Final de su Congreso Constituyente, el que señala que "Exigiremos que se derogue el Código del Trabajo, impuesto por la dictadura y se dicte una legislación, con activa participación de la C.U.T., inspirada en los principios de protección del trabajador y de la libertad sindical y de negociación colectiva" (Araya, 2015, p. 198).

Sin embargo, también existen evidentes diferencias sociológicas con el período previo al golpe de 1973. Si en el período anterior el gobierno y el parlamento eran los interlocutores principales de un sindicalismo liderado por partidos, donde la relación con los empresarios era de confrontación abierta (ver, por ejemplo, Díaz-Corvalán, 1993); con la firma de los "Acuerdos Marco" se buscaba inaugurar un nuevo período marcado por el diálogo y la moderación, donde destaca el intento de fundar relaciones industriales en diálogo con los empresarios (Frank, 1994, p. 581).

¿Qué habría motivado este giro en el sindicalismo en momentos en que se venía saliendo de un gobierno autoritario de derecha?

De acuerdo con diversos autores, la estrategia de diálogo de la multisindical se explica ya que el eje PS-DC, con indiscutible liderazgo dentro de la CUT, apostó por asegurar la institucionalidad democrática para desde ahí avanzar en reformas más profundas para el sindicalismo (ver, por ejemplo, Araya, 2018; Osorio y Gaudichaud, 2015). Como declaró el mismo presidente de la Central en 1990, Manuel Bustos, "la 
promoción y defensa de los intereses de la clase trabajadora están íntimamente ligadas al afianzamiento de la democracia y la estabilidad política de Chile" (La Época, 24/04/1990).

Estos acuerdos allanaron el camino para promulgar la primera reforma laboral del gobierno de Aylwin. En dicha reforma, la primera desde la transición a la democracia, hubo pequeños avances, sobre todo en cuanto a resguardo de derechos individuales de trabajo, como el aumento en los costos de despidos. No obstante, y pese a las tímidas presiones que ejerció la multisindical, no se tocó ningún pilar fundamental del modelo laboral (Narbona, 2015). En este contexto, Manuel Bustos, a pesar de ser crítico de la Reforma Laboral, señaló que era un momento para aprovechar los pequeños avances que ofrecía la Reforma para intentar fortalecer el sindicalismo (El Siglo, diciembre 1991).

Es así como la línea político-estratégica planteada por la CUT queda supeditada a los objetivos de la transición política, lo que inevitablemente generó las primeras tensiones importantes en las bases de la multisindical, así como con el ala más de izquierda dentro de la central liderada por el Partido Comunista. A fines del año 1990, se plantea en El Siglo, periódico del Partido Comunista, que "Fracasó la estrategia de la CUT, pues no se materializó el derecho a huelga, ni el derecho a la negociación colectiva libre. El problema no es un Programa de Gobierno, sino que fracasó la forma de hacer política: una táctica de acuerdos cupulares que deja fuera de toda participación -real y directa- a las organizaciones sindicales" (El Siglo, diciembre, 1990).

Pese a estas diferencias, la CUT terminaba el gobierno de Aylwin bastante unida en sus cúpulas dirigenciales. Una huelga general, como las que empezaron a acontecer una década después, era impensable por aquellos años (revisar Gutiérrez, Medel, Pérez, Pérez y Velásquez, 2019). En ese sentido, tanto la CUT como el gobierno apostaron por reconstruir la matriz clásica del sindicalismo previo al golpe de 1973, donde las relaciones entre sindicatos y partidos estaban altamente imbricadas. Pero ni los partidos ni los sindicatos eran los mismo, y las consecuencias de esta apuesta se harían sentir en las primeras fracturas dentro de la multisindical en el gobierno del segundo presidente de la transición, Eduardo Frei.

Los resultados en materia laboral obtenidos por el gobierno de Aylwin en el primer gobierno de transición fueron interpretados por Frei como un camino a seguir, sobre todo en cuanto a no modificar sustancialmente el modelo laboral de la dictadura. Durante la cuenta pública de su primer año de gobierno, el nuevo presidente se limitará a plantear que se deben modernizar las relaciones laborales, y que, para ello, las tareas serían "elevar la calidad de los empleos, perfeccionar sus instrumentos de capacitación y promover sistemas de relaciones laborales equitativos, adecuados a las necesidades de flexibilidad de los mercados de trabajo...perfeccionar nuestra capacidad fiscalizadora, mejorar las protecciones de seguridad social tanto para los 
trabajadores activos como pasivos, y avanzar en mecanismos diversos e innovadores de participación a todos los niveles" (El Mercurio 22/05/1994, citado en Osorio, 2015, p. 66).

Con estos antecedentes, no llama la atención que la unidad que mostraba la CUT los primeros años de la transición se quebrara. El primer episodio ocurrió a fines de 1994, cuando dirigentes ligados a la Central Latinoamericana de Trabajadores (CLAT) emprenden el camino de la formación de la Central Autónoma de Trabajadores (CAT). En opinión de Frías, esta ruptura "representa un intento que ha estado muchas veces presente en nuestro mundo sindical, en sectores de Sindicalistas Cristianos que enfatizan un Sindicalismo autónomo e independiente" (Frías, 2008, p. 123).

Se podría señalar que la etapa puramente concertacionista de la CUT termina con el gobierno de Aylwin, a partir de cuando comienzan a agudizarse las contradicciones dentro de la central. Sin embargo, las consecuencias que esta etapa concertacionista de la CUT tuvo para el sindicalismo en Chile están presentes hasta la actualidad. De acuerdo con Osorio, la política de la CUT en estos primeros años de democracia, tendiente al diálogo y la paz social, no era un reflejo de las bases sindicales. Su política tuvo más bien un rol de contención y de mediación entre las partes en busca de acuerdos que terminaran con las movilizaciones y permitieran la profundización democrática (Osorio, 2015, p. 90). Ello dejaba en pausa el apoyo real que la Central ofrecía al sector privado, afecto por la legislación laboral de la dictadura, mas no así su apoyo al sector público. Por el contrario, el vínculo entre la Central y las federaciones de los empleados públicos se vio fuertemente fortalecida en esta época (Barret, 2001, p. 590).

En efecto, el sector público es el único que logró “de hecho" realizar negociaciones ramales, en la llamada "mesa del sector público", donde todas las federaciones vinculadas al Estado se unen de manera anual para la negociación del reajuste salarial, lo que se transformó en la mayor institución informal del sindicalismo post transición (Quiroga et al., 2016). Para estas negociaciones el rol de la CUT fue fundamental, sobre todo como mediadora entre partidos, gobierno y federaciones del sector público. De acuerdo con Quiroga et al. (2016), ha habido más acuerdos que desacuerdos en el reajuste del sector público, lo que refleja el éxito de estas negociaciones ramales y de la fuerza sindical de este sector.

La contracara, es que los años posteriores al gobierno de Aylwin, el distanciamiento entre la dirigencia de la CUT y las bases sindicales del sector privado se hacía más patente. La orientación política de la CUT había generado ya las primeras fracturas dentro del sindicalismo chileno. Esto se ve reflejado en un éxodo masivo de los sectores privados del sindicalismo vinculado a la Central a fines de la década de los noventa. De hecho, la afiliación a la CUT pierde cerca de 150 mil afiliados entre comienzos de la transición y fines de los 2000, principalmente por una pérdida de influencia del sindicalismo del sector privado (ver, Osorio, 2015). 


\section{Un último intento de unidad: el giro sociopolítico de la Central}

En un escenario de pérdida relevante de bases sindicales y de incapacidad política evidente de la Central, una nueva generación de dirigentes comenzaba a presionar por una redefinición política de la multisindical que le permitiera recuperar su relevancia en el sindicalismo del sector privado. Ello implicaba recuperar la demanda histórica de un nuevo plan laboral. Diversos registros e investigaciones de historia reciente muestran cómo la Central transitó, a comienzos de la década del 2000, desde un sindicalismo concertacionista a uno más radical y crítico del modelo, también llamado sindicalismo sociopolítico (Araya, 2018; Osorio, 2015). El objetivo del sindicalismo sociopolítico o social es cambiar aspectos de la sociedad sobre la base de una crítica moral del orden existente. Si bien no deja de lado el interés económico "racional" (propio del sindicalismo más bien corporativo), se apunta hacia el gobierno como parte de una lucha más amplia por el avance de la clase trabajadora en términos políticos y sociales (Ross, 2007).

El distanciamiento entre los gobiernos de la concertación y la multisindical se acentúan aún más en el gobierno de Lagos, ya que por un lado la Central se movía hacia la izquierda y se planteaba más radical en su crítica hacia el modelo económico, mientras que, por otro lado, el naciente gobierno del socialista Ricardo Lagos se negaba, una vez más, a realizar cambios profundos al modelo neoliberal laboral (Campero, 2007, p. 34).

El año 2001 el gobierno de Ricardo Lagos promulgó lo que sería la segunda gran reforma laboral post transición. Entre lo más relevante de esta propuesta, se endurecía el castigo a los empleadores que atentaban contra la libertad sindical, se permitía que la Dirección del Trabajo investigara prácticas antisindicales, se reducía la jornada laboral de 48 a 45 horas semanales, y se disponía una serie de medidas pro-empleo, incluyendo la flexibilización. Si bien nuevamente hubo avances a nivel individual, las medidas contenidas en la propuesta de Reforma Laboral se enmarcaban en una clara línea de continuidad con el Código Laboral. Por lo que la CUT, ya presidida por el socialista Arturo Martínez, se manifestó abiertamente contraria a la reforma laboral.

Las contradicciones que generó esta reforma terminaron de cimentar el camino para el congreso refundacional de la CUT, cuyo principal objetivo era modificar sustancialmente su declaración de principios. Este congreso refundacional se realiza el 21 al 23 de agosto del 2003 con cerca de 700 delegados oficiales.

Este momento de mayor confrontación declarada por parte de la multisindical generó reacciones en sectores más moderados. Ello se decanta finalmente en un nuevo quiebre relevante de la CUT, surgiendo oficialmente en mayo del 2003 la Unión Nacional de Trabajadores (UNT). La impronta diferenciadora de esta nueva Central, en relación con la CUT, es que busca estar más abierta al diálogo con el Gobierno y los empresarios. 
En cuanto a las consecuencias que tuvo este giro en las dinámicas de movilización, uno de los acontecimientos más relevantes del año 2003 a nivel sindical, pero también a nivel social, fue que la CUT se dispuso a organizar un gran Paro Nacional el 13 de agosto, como una forma de posicionar definitivamente su agenda en el debate nacional. Este Paro fue el primero de su tipo desde la Dictadura y es visto por muchos estudiosos del sindicalismo como un punto de inflexión en la orientación política de la Central (Osorio, 2015).

Pese a este documentado giro sociopolítico de la central a comienzos de los 2000, la central fue incapaz de ser lo suficientemente fuerte políticamente como para impactar en la institucionalidad de manera decisiva. Gran parte de las explicaciones que dio la clase política y el propio sindicalismo vinculada a la CUT acerca de la ausencia de reformas en el período alude a las limitaciones institucionales que enfrentaron los gobiernos de la Concertación, también llamados enclaves autoritarios (Garretón, 2004). Los más aludidos suelen ser el sistema binominal y los senadores designados. Ambos mecanismos aseguraban, por lo menos, una minoría relevante de políticos de derecha en el parlamento capaces de bloquear cualquier iniciativa de reforma al plan laboral en sus pilares fundamentales.

Sin embargo, ninguno de esos enclaves autoritarios persistió para el segundo gobierno de Michelle Bachelet. Luego de la reforma constitucional de 2005, los nueve senadores designados que solían aumentar el poder de veto de la derecha fueron eliminados, e incluso la Concertación tenía la mayoría de los escaños en ambas cámaras. Era el contexto apropiado para plantear una nueva reforma laboral. Meses antes de las elecciones, el 11 de julio de 2013, la CUT convocó a una huelga general con miras a incidir en el programa de gobierno (Pérez, 2017). La incorporación de una reforma laboral al programa presidencial de Bachelet fue el resultado directo de las presiones del Partido Comunista y la CUT.

Si bien el proyecto de reforma laboral era bastante más ambicioso en un principio, fue perdiendo fuerza en la discusión legislativa hasta ir perdiendo uno por uno todos los puntos que tocaban los pilares fuertes del plan laboral.

El resultado fue, sorprendentemente, muy parecido al de reformas anteriores De acuerdo con el experto en derecho laboral, José Luis Ugarte, una vez más la reforma laboral no toca los pilares del plan laboral, e incluso la tilda como un "retroceso" (Ugarte, 2016).

Incluso en la situación más favorable desde el retorno a la democracia, sin los enclaves autoritarios y con una relativa mayoría en el congreso, la CUT careció de la fuerza necesaria para incidir políticamente y cambiar en aspectos sustantivos la institucionalidad del plan laboral.

Pero esta ausencia de reformas no fue por una ausencia de intencionalidad de cambio, sino a una falta de fuerza justamente en el sector sindical más afectado por 
la reforma laboral, el privado. El sector público, donde más músculo tenía la Central, más que adoptar una posición ofensiva, usó una fuerza más bien defensiva para que dicho código no llegara a sobre-regular las relaciones colectivas dentro del sector público (Seymour, 2015). El clivaje fuerte del sindicalismo se mantenía una relación cercana a la Central, pero sus intereses no se movían por la demanda de un nuevo código laboral.

\section{De la división estructural a la contraposición de identidades}

El concepto de clivajes no debe confundirse con una simple división social, así como tampoco con un comportamiento colectivo sin bases estructurales. De acuerdo con Bartolini y Mair (2007), la peculiaridad del concepto de clivaje es su capacidad de unir lo social con lo ideológico y con las divisiones conductuales/organizacionales. En concreto, para observar clivajes, tienen que haber tres elementos constitutivos: a) debe haber una división estructural; b) se deben activar identidades colectivas o ideologías en torno a esas divisiones; y c) debe haber una organización o comportamiento colectivo en torno a esas identidades (Bartolini, 2011).

Chile ha tenido históricamente una composición heterogénea en su sindicalismo (Angell, 1974; Barrera, 1980) , y a pesar de ello, previo al golpe de Estado, éste lograba articularse como una fuerza impulsada principalmente por la CUT y los partidos políticos. Sin embargo, como se expuso en las secciones anteriores, durante los primeros años de transición, se visibilizaba un evidente abandono de la CUT en torno a las demandas del sector privado. Cuando un sector del sindicalismo vinculado a la CUT apostó por una política subordinada a los lineamientos de los partidos de la Concertación, se generó un rezago en su capacidad de avanzar en el programa general relativo a la derogación de un código laboral. A partir de eso se puede distinguir claramente la consolidación de la CUT en el sector de trabajadores vinculados al Estado, mientras que se iba deteriorando su fuerza en el sector privado.

Siguiendo la literatura de clivajes que reivindica el rol que las élites políticas pueden tener en la conformación y modificación de clivajes sociales (Chibber y Torcal, 1997), se plantea que este período Concertacionista de la Central fue clave para entender la politización de la división público-privado en el sindicalismo chileno. Los dos clivajes que se conformaron al calor de los procesos iniciales de democratización no lograron ser revertidos con el giro socio político de la CUT, y se mantuvo una división que consolidó un sector fuerte y unido, y otro débil y atomizado.

Publicaciones académicas recientes han recogido una diversidad de testimonios de dirigentes sindicales del sector público y privado que reflejan la consolidación de una identidad sindical articulada en torno a la CUT y los partidos (ver, por ejemplo, Urrutia, Osorio y Campusano, 2015; Medel, 2017; Osorio y Campusano, 2020). 
El Centro de Investigación Político Social del Trabajo (CIPSTRA), el año 2015 realiza un trabajo donde entrevista a más de 40 dirigentes sindicales del sector público y del sector privado que participaron en Huelgas el año anterior (Urrutia et al., 2015). Ese material también es analizado por Medel (2017), donde va exponiendo un relato sistemático en los dirigentes del sector privado en abierta oposición a la CUT, a la cual acusa de esta subordinada a los partidos y de defender únicamente los intereses de los trabajadores públicos (Medel, 2017). Los relatos dejan ver una fuerte ideología anti Central y antipartidos en el sindicalismo del sector privado, el que no ve conveniente generar vínculos con la CUT. En el discurso de los dirigentes del sector privado, se deja ver el asilamiento político en el que se encuentran y el poco margen de acción que tienen, al estar presos de una institucionalidad laboral que no los favorece.

Desde la otra vereda, el sector público manifiesta una cercanía con los partidos políticos y, sobre todo, con la CUT. Las alianzas con las centrales son un elemento altamente mencionado y relevante para las huelgas del sector público y, en general, los dirigentes saben que pueden contar con el apoyo de la CUT. En el sector público los partidos políticos son funcionales para las luchas de los trabajadores, ya que, al estar habitando las principales centrales, los necesitan para llevar a cabo sus negociaciones con el gobierno de manera sectorial (Medel, 2017).

Las redes que mantiene el sector público van más allá incluso de la CUT, es un sindicalismo articulado con otros sectores, con alianzas amplias de otros gremios y centrales. Este enorme apoyo externo cierra gran parte de la explicación respecto a la capacidad que ha mostrado dicho sector de mantener huelgas ilegales, con grados de reconocimiento importantes, aunque no formales, por parte de los gobiernos de turno (Gutiérrez, Medel, Pérez y Velásquez 2017; Quiroga et al., 2016).

A partir de un estudio de alianzas en las huelgas laborales llevadas a cabo por federaciones, en la siguiente sección se busca poner a prueba una hipótesis principalmente descriptiva: que las federaciones del sector público son las que encuentran mayor densidad de alianzas entre ellas, generando un clivaje claramente diferenciado del sindicalismo del sector privado, el que se encuentra atomizado y aislado políticamente.

\section{De la contraposición de identidades al comportamiento organizativo}

\section{El estudio desde las huelgas laborales}

El mejor prisma para observar comportamiento organizacional en torno a identidades sindicales es por medio de las alianzas en las huelgas laborales. Una huelga es el escenario donde los sindicatos ponen en movimiento todos los recursos de poder internos y externos con los que cuentan, por cuanto los resultados pueden ser decisivos para el futuro de las relaciones laborales de la empresa o institución. Un término favorable del conflicto para los trabajadores puede fortalecer sus organizaciones, dotarlos 
de mejores condiciones laborales, o incluso generar efectos políticos a nivel macro (Murillo, 2001); pero uno negativo puede terminar con despido de trabajadores, con sindicatos atomizados o simplemente destruidos (Urrutia et al., 2015). Es así como un estudio sistemático de la huelga laboral da luces no sólo de tendencias de conflictividad en cada país, sino también de la estructura de alianzas y relaciones externas que mantienen los sindicatos en distintos períodos históricos.

Pero no todas las huelgas son igualmente relevantes para observar la capacidad de influencia en la política, esto ya que son las federaciones y confederaciones los principales agentes del sindicalismo sociopolítico, en contraposición con el sindicalismo corporativo más propio de los sindicatos de base.

Las huelgas de federaciones suelen representar a sectores de la economía, por tanto, buscan ir un paso más allá de las reivindicaciones pecuniarias de una empresa o institución, intercediendo en pos de múltiples sindicatos en relaciones generalmente mediadas o antagonizadas por el Estado.

En la siguiente sección se muestran datos obtenidos del Observatorio de Huelgas Laborales del COES-UAH, y se utilizan un filtro: se consideran solamente huelgas realizadas por federaciones o confederaciones. Los datos disponibles cubren desde el año 2010 hasta el 2019. El contexto del estallido social del 2019 se podría tomar como una coyuntura crítica que genera el riesgo de sesgar los resultados, o bien, de incluir un período que forma parte de otra etapa histórica. Por lo mismo, para el 2019 se consideran los datos únicamente hasta una semana previa al estallido social del 18 de octubre de $2019^{2}$. Si bien el estallido social no forma parte del foco de este artículo, si se ofrece una reflexión sobre el impacto que puede tener la huelga general del $12 \mathrm{de}$ noviembre del 2019 en las conclusiones.

Luego de aplicado ambos filtros, el resultado da un total de 494 huelgas laborales realizadas por federaciones y confederaciones entre 2010 y 2019. El poder movilizador y las relaciones entre estas federaciones permitirán evaluar dónde están los sectores fuertes del sindicalismo chileno desde la óptica de las alianzas y su poder movilizador.

En la Figura 1 se observa el total de huelgas por federaciones realizadas desde el 2010, donde se observa la naturaleza cíclica de la conflictividad laboral, con un mínimo de 34 el año 2011 hasta un máximo de 84 el 2016.

2. Los datos de las alianzas para cada año están disponibles bajo solicitud al autor. 


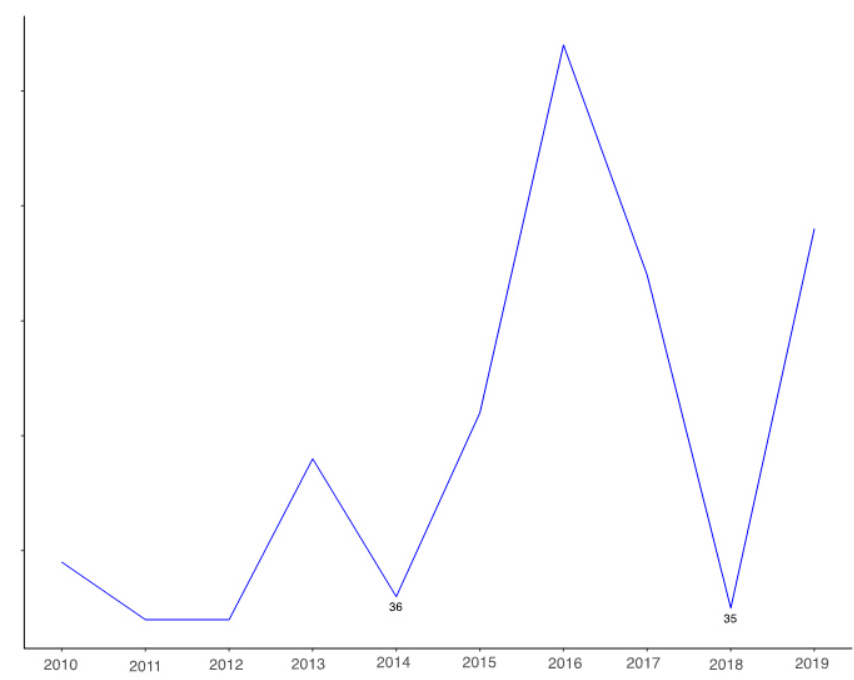

Figura 1. Huelgas con participación de Con/Federaciones (2010-2019)

Fuente: Elaboración propia en base a base de Huelgas Laborales Coes-UAH.

Tomando como referencia este análisis cuantitativo de huelgas de federaciones y confederaciones en Chile entre los años 2010 a 2019, se puede señalar que son seis las federaciones fuertes en el sindicalismo chileno: la Federación de Trabajadores del Cobre (FTC), la Unión Portuaria, la Confederación de Trabajadores de la Salud Municipal (Confusam), el Colegio de Profesores, la Asociación Nacional de Empleados Fiscales (Anef) y la Federación de Nacional de Trabajadores de la Salud (Fenats). Las últimas cuatro federaciones mencionadas pertenecen al sector público, mientras que la FTC se trata de una federación que agrupa a los sindicatos vinculados a una empresa del Estado (Codelco). Es decir, sólo la Unión Portuaria dentro de las federaciones grandes no está vinculado al Estado. El resto de las agrupaciones no alcanzan un mínimo de huelgas para reagruparlas, por lo que quedan agrupadas en dos categorías que son: otras federaciones del sector privado y otras del sector público.

La Figura 2 muestra la frecuencia de huelgas por federación entre el 2010 y 2019. La mayoría de las huelgas (92) fueron llevadas por la Fenats. Luego le siguieron otras federaciones del sector privado, el Colegio de Profesores y la Anef. Las con menor cantidad de huelgas fueron la Confusam y la FTC. Aunque el poder movilizador de una federación se puede medir por medio de la frecuencia huelguista para un período determinado, ello puede llevar a equívocos. Una federación relativamente débil puede parar muchas veces y movilizar a sólo un puñado de trabajadores en cada huelga. Mientras que otras federaciones más fuertes puede realizar una huelga al año, pero movilizando a masas inmensas de trabajadores. De ahí que diversos autores señalen que lo más correcto sea observar promedio de trabajadores comprometidos antes que simplemente la frecuencia huelguista (Gutiérrez et al., 2019). 


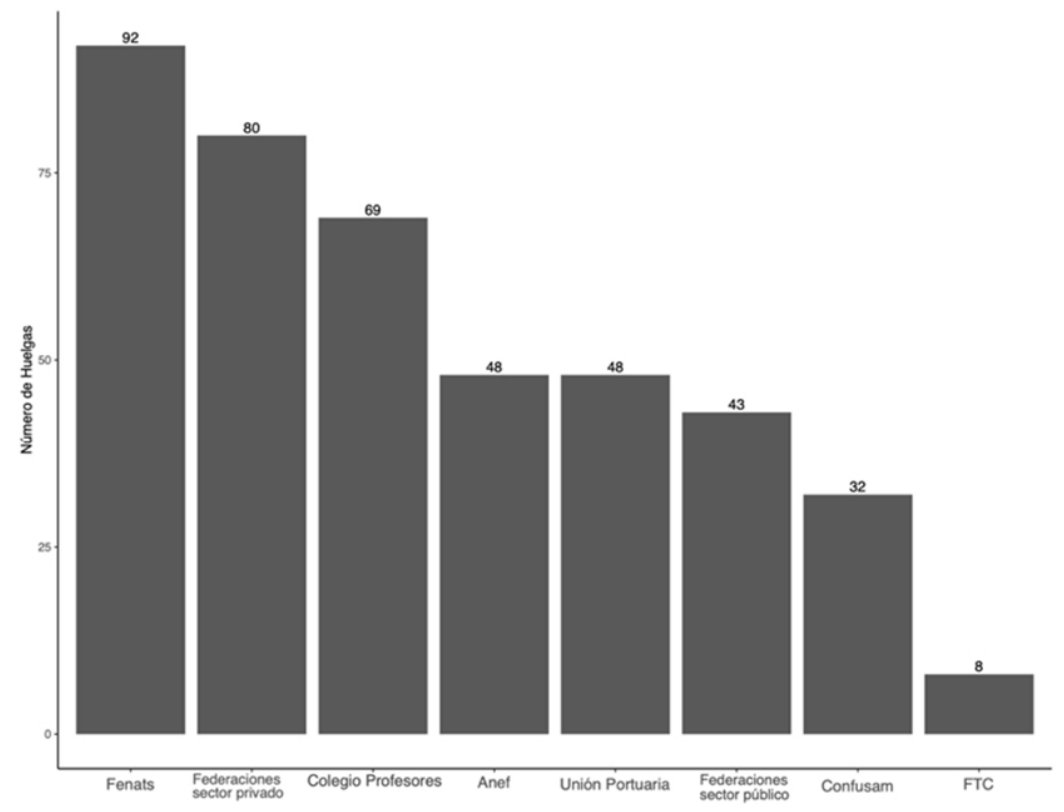

Figura 2. Huelgas de Con/Federaciones (2010-2019)

Fuente: Elaboración propia en base a base de Huelgas Laborales Coes-UAH.

En la Tabla 1 se observa el promedio de trabajadores comprometidos (TC) por huelga y la suma de todos ellos para el período desde el 2010 al 2019. Hay que advertir que estos promedios y sumas cuentan las huelgas donde está presente dicha federación, pero puede haber otras federaciones presentes en la misma huelga, por lo que no necesariamente es una cifra que refleje exclusivamente a miembros de esa organización suprasindical. Considerando lo anterior, se ve un claro predominio de la Anef, que cuando participa en una huelga, se moviliza un promedio cercano a los 73 mil trabajadores. Para el período 2010-2019, las huelgas en las que ha participado la Anef suman a más de 2.2 millones de trabajadores. Le siguen, en orden, el Colegio de Profesores (20,654 TC en promedio), la FTC (17,628 TC en promedio) y la Confusam (12,086 TC en promedio). Bastante más abajo se encuentran las otras Federaciones del sector público y privado, con un promedio cercano a 2 mil trabajadores. 
Tabla 1. Características de las principales Con/Federaciones 2010-2019.

\begin{tabular}{|l|c|c|}
\hline \multicolumn{1}{|c|}{ Organización } & Media TC & Suma TC \\
\hline Anef & 73,524 & $2,205,738$ \\
\hline Colegio Profesores & 20,654 & $1,032,703$ \\
\hline FTC & 17,628 & 123,399 \\
\hline Confusam & 12,086 & 205,475 \\
\hline Fenats & 2,901 & 168,315 \\
\hline Federaciones sector privado & 2,046 & 130,952 \\
\hline Federaciones sector público & 2,391 & 645,62 \\
\hline Unión Portuaria & 1,606 & 54,593 \\
\hline
\end{tabular}

Fuente: Elaboración propia en base a base de Huelgas Laborales Coes-UAH.

En la misma Tabla 1 también se observa cómo la Fenats, pese a paralizar mucho, no logra movilizar en promedio muchos trabajadores por huelga. Esto ha sido tratado en el libro de Álvarez (2017), quien describe cómo la Fenats pasó de ser una única gran Federación de la salud en los años 90 a vivir una serie de divisiones que mermaron su capacidad de movilización, dejándola altamente fragmentada como se encuentra ahora (muchas huelgas, poca capacidad movilizadora).

\section{Las alianzas dentro del sindicalismo chileno}

¿Cuál es la relación de alianza o lejanía entre las federaciones involucradas en el estudio? ¿Cómo se relacionan estas con la CUT?

De acuerdo con el argumento de este artículo, en la comprobación empírica se debería observar una relación más fluida entre la CUT y las federaciones del sector público, mas no así con el sector privado, para el período 2010 al 2019. La base de datos del OHL tiene la virtud de que codifica huelgas que pueden ser inter-organizacionales o bien, huelgas que cuentan con el apoyo de otras organizaciones sindicales. Es decir, cada vez que en las noticias se menciona más de una organización, o bien, que hubo otra organización que prestó apoyo explícito en la huelga, ello queda registrado en la base de datos. La base de datos también contiene los apoyos brindados por otras organizaciones de la sociedad civil no sindicales, por lo que se incluye también un segundo resultado que incluye otras alianzas sociales con las que cuenta cada una de las federaciones.

Ese procedimiento no está exento de posibles sesgos, es posible estar presente en una huelga y no prestar ayuda sustantiva. También es posible que las organizaciones se presten ayuda sin necesariamente estar presente en el lugar de la huelga, o puede que lo hayan estado, pero aquello no haya quedado registrado en un medio de prensa, material primario para la codificación de la base de datos. Cómo última observación, como la base de datos del OHL se codifica a partir de la prensa, es posible que no toda 
la realidad huelguista esté expresada en dicha base de datos, más aún considerando que para codificar la ayuda de otra organización debe haber una mención explícita en la prensa, por lo que dicho apoyo debe haber sido sustantivo.

Considerando todo lo anterior, estar presente en la movilización de otra federación de manera activa debería estar reportado en la prensa, lo que implica que también debería estar capturado en la base. Hay que resaltar que la metodología del OHL tiene una alta confiabilidad ${ }^{3}$ y ofrece los mejores datos cuantitativos con los que se puede estudiar a la realidad huelguista en Chile. Por último, la variable de apoyos o alianzas prestada al grupo movilizado principal es una buena aproximación para cercanía organizacional, tal como se ha reportado en estudios previos (ver, por ejemplo, Wada, 2014; Krinsky \& Crossley, 2014).

En la Figura $3^{4}$, se observa la representación gráfica de estas alianzas. Cada nodo representa una Federación o Confederación, donde se incluye también a la CUT, mientras que cada línea representa una huelga en que ambas Federaciones o grupos de Federaciones colaboraron. Para el gráfico se toma en cuenta la distribución espacial de los nodos, de manera tal que los nodos que se encuentren más próximos entre sí mantienen relaciones sociales y políticas más estrechas que aquellos que se encuentren más distanciados.

En la Figura 3 se observan las relaciones entre federaciones y la Central, donde queda en evidencia que la CUT mantiene alianzas virtuosas principalmente con el colegio de profesores y con la Anef. La CUT también mantiene relaciones menos densas con Fenats, Confusam y la Unión portuaria. Se ve también que existe una red de alianzas entre la Fenats, con otras federaciones del sector público y, en menor medida con la Anef. La Confusam se ha movilizado en conjunto con la CUT, pero su principal aliada es la Anef, aunque no de manera particularmente densa. Llama la atención que en los 10 años de registros huelguistas las federaciones del sector privado, que se han movilizado mucho, hayan recibido tan poco apoyo explícito de otras organizaciones suprasindicales, lo que deja en evidencia su aislamiento. Su único vínculo es con la Unión Portuaria, y en la base de datos del OHL, no hay registros de que una huelga realizada por una Federación del sector privado haya recibido apoyo explícito de la CUT. Con esto no se puede señalar que dicho apoyo no haya existido en la práctica, sino que dicha alianza no fue lo suficientemente notoria como para haber sido capturado por la metodología de codificación realizado por el OHL ${ }^{5}$.

3. Para revisar anexo metodológico escribir al autor.

4. Para realizar la representación gráfica de las redes se utiliza el programa R .3.6.2 y el paquete igraph.

5. La metodología de codificación del OHL se realiza en base a una revisión de múltiples diarios nacionales y regionales. 
Lo anterior contrasta con las otras Federaciones del sector público, donde tres de los cuatro grandes (representados por la Anef, la Fenats, y la Confusam), han prestado su apoyo explícito a otra Federación del sector público.

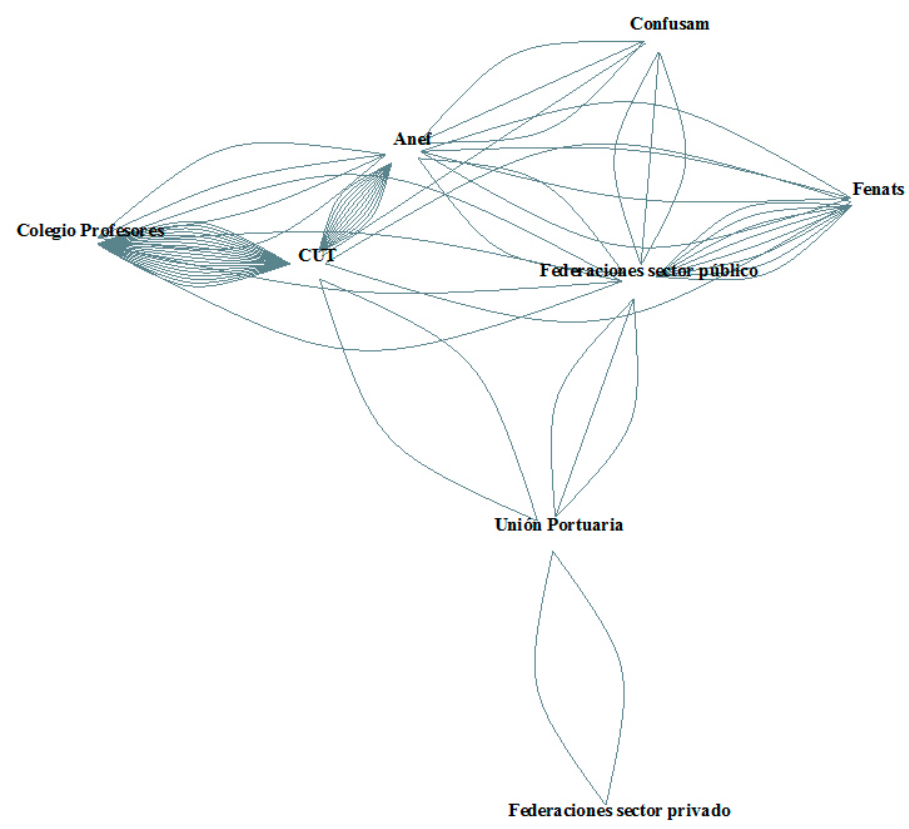

Figura 3. Alianzas en las huelgas de Con/Federaciones (2010-2019)

Fuente: Elaboración propia con la base del OHL, 2010-2019.

La Federación de trabajadores del cobre quedó excluido del gráfico ya que en los años para los cuales hay registro no hay datos de que se hayan movilizado en conjunto con otra federación o con la Central. Esto refleja dos cosas. Primero, que se trata claramente de una federación que no necesita de alianzas para llevar a cabos sus movilizaciones, por cuanto su capacidad de impactar en la opinión pública y posición estratégica en la economía chilena le permiten esa prescindencia. En segundo lugar, muestra que, pese a ser el único grande del sindicalismo vinculado a la CUT que está afecto al código laboral, no mantiene relaciones cercanas con la CUT ni con ninguna otra federación del sector público. Gran parte del aislamiento de la FTC se puede explicar por el carácter excluyente de la federación respecto a la Confederación de Trabajadores del Cobre (CTC), una organización nacional autónoma y exclusivamente de contratistas. De acuerdo con Manky (2019), la FTC siembre mantuvo acuerdos marcos propios con CODELCO, y pese al crecimiento de los trabajadores externalizados, no cambió su estrategia de exclusión respecto de los contratistas. Al estar la CTC muy vinculada al PC, es entendible que la FTC haya mantenido un camino de vinculación moderada con la CUT, lo que se refleja en la soledad de sus paralizaciones. 
Más allá de las alianzas entre federaciones y confederaciones, la base de datos del OHL considera también la alianza entre huelguistas y otros actores $u$ organizaciones de la sociedad civil. En la Figura 4 se incluyen tres nodos, los que corresponden a Estudiantes, Autoridades locales y Sociedad civil. Esta última agrupa a organizaciones no gubernamentales, así como otros movimientos sociales no sindicales.

La Figura 4 muestra las fuertes alianzas que han desarrollado organizaciones estudiantiles con el sindicalismo, especialmente con el Colegio de Profesores. Por su parte, resulta interesante observar que las federaciones del sector privado desarrollan ciertas alianzas con estos otros actores no sindicales, principalmente con autoridades locales y con organizaciones de la sociedad civil. Sin embargo, mantiene una relación débil con el principal aliado del sindicalismo: los estudiantes. Pese a estas nuevas alianzas con actores no sindicales, se mantiene el aislamiento del sector privado, lo que se grafica bastante bien en la Figura 4 al ver la distancia entre la Central y las federaciones del sector privado.

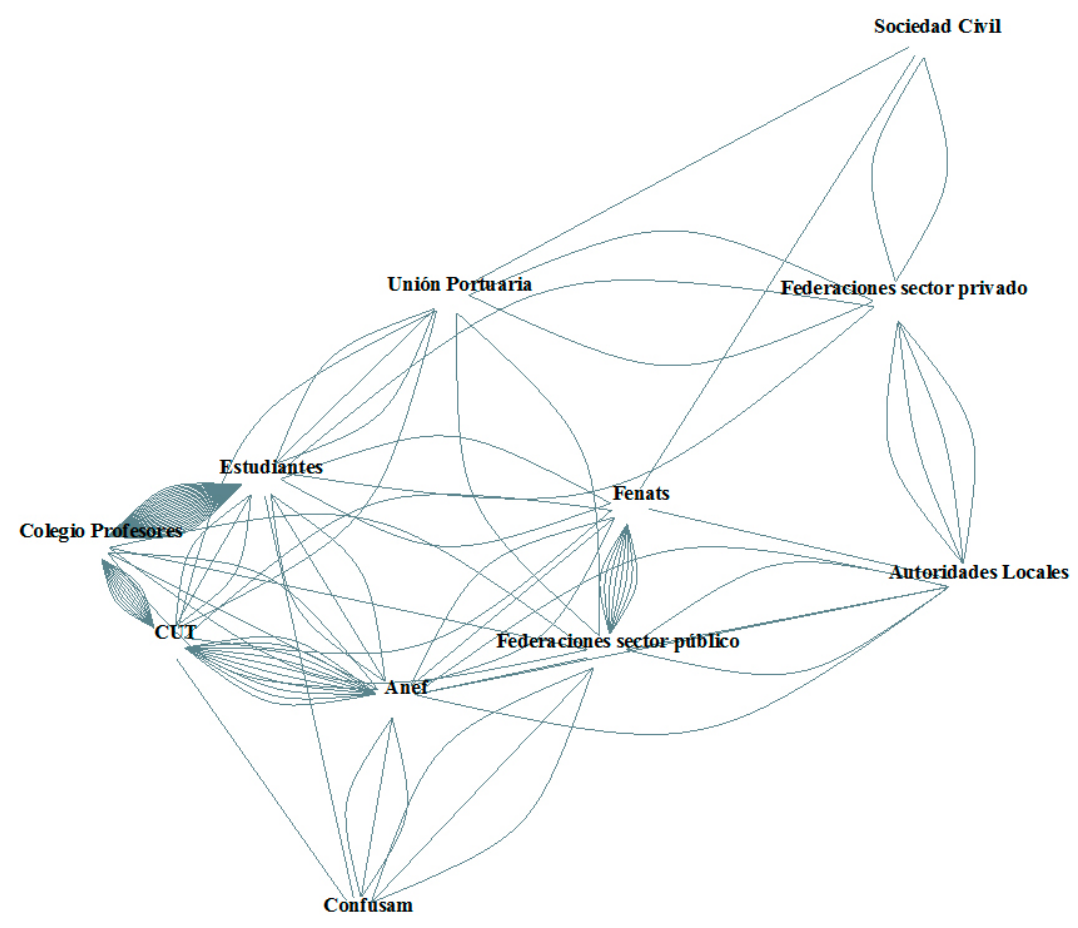

Figura 4. Alianzas en las huelgas de Con/Federaciones (2010-2019) incluyendo a actores no sindicales.

Fuente: Elaboración propia con la base del OHL, 2010-2019. 
Finalmente, resulta relevante decir algo acerca de la centralidad de las redes. La centralidad tiene que ver con la capacidad que tiene un nodo (o federación) para conectar con los otros actores en la red como un todo.

Para este caso se utiliza la noción de centralidad entendida como "grado" (o degree). La pregunta no es si una federación tiene muchos vínculos - ya que puede tener muchas alianzas con un mismo nodo-, sino cuántas conexiones con otros nodos tiene una federación. Esto a menudo se toma como una medida de prestigio. Una Federación muy conectada con otras indica algo sobre su importancia y, potencialmente, su poder (Krinsky \& Crossley, 2014). Por su parte la centralidad de cercanía indica qué tan cerca está un nodo de todos los demás nodos de la red. En la Tabla 2 se presentan los resultados de la centralidad de grado y de cercanía. La Federación con mayor grado de centralidad resulta ser, como era esperable, la CUT. Luego vienen las federaciones grandes del sector público vinculadas a la CUT. El nodo más aislado, tanto en centralidad como en cercanía, resulta ser el correspondiente a las federaciones del sector privado.

Tabla 2. Medidas de Centralidad.

\begin{tabular}{|l|c|c|}
\hline \multicolumn{1}{|c|}{ Organización } & Centralidad & Cercanía \\
\hline CUT & 5 & 0,78 \\
\hline Anef & 3,4 & 0,7 \\
\hline Otras del sector publico & 2.9 & 0,77 \\
\hline Fenats & 2,14 & 0,58 \\
\hline Colegio Profesores & 3.8 & 0,58 \\
\hline Confusam & 1 & 0,58 \\
\hline Unión Portuaria & 1 & 0,63 \\
\hline Otras del sector privado & 0,28 & 0,41 \\
\hline
\end{tabular}

Fuente: Elaboración propia en base a base de Huelgas Laborales Coes-UAH.

En síntesis, se puede observar que cuando hablamos de la capacidad movilizadora de las federaciones del sindicalismo chileno, lo que hay es básicamente un sindicalismo desbalanceado en cuanto a poder y alianzas. Primero están las federaciones grandes del sector público, fuertes y altamente conectadas entre sí; luego, una federación de una empresa estatal (FTC), fuerte pero aislada del resto; y, finalmente, todas las otras federaciones del sector privado, débiles y aisladas social y políticamente. 


\section{Conclusiones}

Aunque la composición del sindicalismo chileno post dictadura es heterogéneo y tiene presencia en diversas ramas de la economía, su capacidad movilizadora, sus identidades y su comportamiento organizacional está fuertemente definido en torno a una división estructural bastante más primaria: el sector público y el sector privado de la economía.

Ambos sectores del sindicalismo partieron la transición a la democracia en posiciones muy distintas. Mientras el sector privado se encontraba preso de una institucionalidad laboral altamente restrictiva, el sector público, en cambio, se movía por fuera del código laboral. En la primera parte de este artículo, se expuso como la CUT, que se refundaba con la clara misión de superar el código laboral de la dictadura, adoptó durante los noventa una postura moderada y alineada con el programa político de la Concertación. Ello generó un abismo con el sindicalismo del sector privado, a la vez que profundizaba sus vínculos con el sector público. En la práctica, la CUT terminó siendo una herramienta política efectiva a la hora de defender la autonomía y los intereses del sector público, pero se fue volviendo incapaz de demostrar la misma presión movilizadora para defender los intereses del sector privado. Esto fue reforzando una distancia ideológica de los sectores público y privado en el sindicalismo chileno, lo que se termina expresando en un comportamiento político y organizacional diferenciado expresado en las alianzas que las federaciones adoptan entre ellas y con la CUT. Es así, como el mismo comportamiento de la Central va politizando esta división estructural entre el sector público y el privado, hasta el punto de conformar los dos principales clivajes sindicales del Chile post autoritario; un sector público fortalecido, tanto en su capacidad de movilización como en sus alianzas con la Central, y un sector privado, alejado de la CUT, aislado y débil en capacidad movilizadora.

Pensar en las capacidades políticas del sindicalismo en Chile desde la perspectiva de los clivajes sindicales resulta relevante para entender las escasas capacidades políticas que ha mostrado tener la CUT en coyunturas recientes. Por ejemplo, permite pensar por qué, para el momento en que la Central dio su giro hacia un sindicalismo sociopolítico (Araya, 2018; Osorio, 2015), su capacidad de incidencia fue tan escaza (Pérez, 2017).

Incluso frente a un contexto favorable para reformar el código laboral, como fue la reforma del segundo gobierno de Bachelet, las bases reales que podía movilizar la Central estaban reducidas a un clivaje sindical fuerte, pero ajeno a demandas de reformas en el código laboral. O, en otras palabras, la alianza de la CUT estaba fracturada justamente con los sectores que más razones tenían para presionar por reformas laborales, a saber, el sindicalismo del sector privado. De esta manera, la CUT se ha reproducido en torno a los clivajes que ella misma ayudó a conformar, más efectiva como plataforma negociadora del sector público que como impulsora de cambios legislativos para el sector privado. 
Otra pregunta que resulta sumamente relevante es de si acaso los eventos recientes en Chile, aquellos posteriores al 18 de octubre del 2019, están abriendo la puerta a un bloque sindical más unido, o por el contrario, dicha articulación descansa en las mismas fuerzas que han dado sustento a la CUT los últimos treinta años. Aunque resulta apresurado decirlo, la llamada Mesa de Unidad Social (MUS), plataforma supra organizacional que ha convocado a sectores sindicales que se encontraban socialmente aislados (principalmente sindicatos del sector privado) y los ha puesto en contacto con directivas de otras organizaciones sindicales y no sindicales. La más llamativa es la Unión Portuaria.

La principal coyuntura sindical en el contexto del estallido fue la huelga general del 12 de noviembre del 2019. Osorio y Velásquez (2021) realizan un análisis pormenorizado de la capacidad movilizadora de la MUS en distintos sectores del sindicalismo. Los autores relatan que las únicas organizaciones que efectivamente paralizaron fueron nuevamente los grandes sindicatos del sector público. Sin embargo, reconocen que hubo una adhesión histórica (cerca del 40\%) en los principales sindicatos de la banca, la construcción y el comercio.

Resta ver si la huelga del 12 de noviembre logra constituirse como una coyuntura crítica capaz de redibujar los clivajes sindicales público-privado. Sólo con la unificación de las fuerzas sindicales se podrá generar el poder movilizador y asociativo necesario para presionar de forma efectiva a la política. El estallido social es una oportunidad política para que la CUT pueda convocar a un sindicalismo heterogéneo. Nuevamente, los dirigentes políticos de la Central y sus decisiones estratégicas tendrán un peso gravitante en definir si los acontecimientos recientes logran reconfigurar a la multisindical, o bien, mantener una continuidad de los clivajes preexistentes.

\section{Referencias}

Angell, Alan (1974). Partidos políticos y movimiento obrero en Chile. Ediciones Era. Álvarez, Rolando (2017). Hijas e hijos de la rebelión. Una historia social y política del Partido Comunista de Chile en postdictadura (1990-2000). LOM Editores.

Araya, Rodrigo (2015). Movimiento Sindical en Dictadura. Fuentes para una historia del sindicalismo en Chile, 1973-1990. Santiago: Ediciones Universidad Alberto Hurtado.

Araya, Rodrigo (2018). La batalla por las reformas laborales. La CUT ante el cerco neoliberal, 1988-2001. Tiempo Histórico: Revista de la Escuela de Historia, (15).

Barrera, Manuel (1980). Desarrollo económico y sindicalismo en Chile: 1938-1970. Revista Mexicana de Sociología, 1269-1296.

Barrett, Patrick (2001). Labour policy, labour-business relations and the transition to democracy in Chile. Journal of Latin American Studies, 33(3), 561-597. 
Bartolini, Stefano y Peter Mair (2007). Identity, competition and electoral availability: the stabilisation of European electorates 1885-1985. ECPR Press.

Bartolini, Stefano (2011). 'Cleavages, social and political'. In B. Badie, D. Berg-Schloss and L. Morlino (eds.) International Encyclopedia of Political Science (pp. 275-282). Thousand Oaks: Sage.

Campero, Guillermo (2007). La economía política de las relaciones laborales 19902006. Serie Estudios Socio/Económicos, 37.

Chibber, Pradeeb \& Mariano Torcal (1997). Elite Strategy, Social Cleavages, and Party Systems in a New Democracy. Comparative Political Studies, 1, 27-54.

Díaz-Corvalán, Eugenio (1993). Nuevos sindicalismos. Viejos problemas. La Concertación en Chile, Revista Nueva Sociedad, 124.

El Siglo, Editorial. edición de diciembre 1991.

El Siglo, Editorial. edición de diciembre, 1990.

Frank, Volker (1994). Acuerdos y conflictos: ¿Signos contradictorios de nuevas relaciones laborales en la transición chilena a la democracia? Revista Estudios Sociológicos, XII (36).

Frank, Volker (2004). Politics without policy: The failure of social concertation in Chile, 1990-2000. En P. Winn (Ed.), Victims of the Chilean miracle: Workers and neoliberalism in the Pinochet era, 1973-2002 (pp. 71-124). Durham, NC: Duke University Press.

Frías Patricio (2008). Los desafíos del sindicalismo en los inicios del siglo XXI. CLACSO.

Foxley, Alejandro y Manuel Bustos (1999). Conversaciones con Manuel Bustos. Andres Bello.

Fundación SOL (2015). Manifiesto laboral: Por un nuevo Modelo de Relaciones Laborales. Recuperado de http://www.fundacionsol.cl/wpcontent/uploads/2013/10/ Manifiesto-por-un-Nuevo-Modelo-de-Relaciones-Laborales.pdf.

Gamonal, Sergio (2011). Derecho colectivo del trabajo. Santiago: Editorial Legal Publishing.

Garretón, Manuel (2004). Incomplete Democracy: political democratization in Chile and Latin America. Chapel Hill: University of North Carolina Press.

González, Julio y Francisco Zapata (2016). El acuerdo marco-tripartidismo en el Chile de los 90: revisión desde una perspectiva hemerográfica. POSTData: Revista de Reflexión y Análisis Político, 21(1): 207-242.

Gutiérrez, Francisca, Rodrigo Medel, Domingo Pérez, Domingo y Diego Velásquez (2017). Informe de Huelgas Laborales 2016. COES-UAH. 
Gutiérrez, Francisca, Rodrigo Medel, Pablo Pérez, Domingo Pérez y Diego Velásquez (2019). Informe de Huelgas Laborales 2019. COES-UAH.

Krinsky, John \& Nick Crossley (2014). Social movements and social networks: Introduction. Social Movement Studies, 13(1): 1-21.

Lipset, Seymour and Stein Rokkan (1967) Cleavage structures, party systems, and voter alignments: An introduction. In: Lipset SM and Rokkan S (eds) Party Systems and Voter Alignments: Cross-National Perspectives (pp. 1-64). New York: Free Press.

Manky, Omar (2019). ¿Los límites del clasismo?: Identidad y vínculos entre trabajadores regulares y precarios. Chile y Perú en perspectiva comparada. Revista Internacional de Sociología, 77(2), 125.

Medel, Rodrigo (2017). Alliances et autonomie politique. Les deux faces du syndicalisme chilien. Cahiers des Amériques latines, (86): 49-69.

Murillo, María (2001). Labor unions, partisan coalitions, and market reforms in Latin America. Cambridge University Press.

Narbona, Karina (2015). Antecedentes del modelo de relaciones laborales chileno. Observatorio Social del Proyecto Plataformas Territoriales por los Derechos Económicos y Sociales (Santiago: Fundación Sol, 2015), Ideas para el Buen Vivir, 6.

Osorio, Sebastián (2015). Trayectoria y cambios en la política del movimiento sindical en Chile, 1990-2010. El caso de la CUT, entre la independencia política y la integración al Bloque Histórico Neoliberal. Facultad de Humanidades, Universidad de Santiago de Chile, Santiago.

Osorio, Sebastián y Frank Gaudichaud (2015). Los caminos del movimiento sindical ante la democracia neoliberal y el legado de la Dictadura, 1990-2015. Democracia versus neoliberalismo, 25, 236-258.

Osorio, Sebastián \& Karim Campusano (2020). El impacto de la huelga en los procesos de politización sindical en Chile. Política y sociedad,57(3): 843-864.

Osorio, Sebastián y Diego Velásquez (2021). El poder sindical en el "Estallido social" chileno. La huelga general de noviembre de 2019. Revista Española de Sociologia [en prensa].

Pérez, Pablo (2017). Empresas, trabajadores y la política de clase de las reformas laborales en Chile, 1973-2016. UC San Diego.

Quiroga, Francisca, Nestor Guerrero, Nestor y Sofía Schuster (2016). Discurso público e institucionalización del conflicto político en Chile: El caso del reajuste salarial del sector público (1990-2014). Gestión y política pública, 25(1): 119-163.

Ross, Stephanie (2007). Varieties of social unionism: Towards a framework for comparison. Just Labour: A Canadian Journal of Work and Society, 11,16-34. 
Seymour, Fernando (2015, octubre 29). Sector público en alerta ante regulación laboral del Gobierno. Diario Universidad de Chile. Recuperado de https://radio. uchile.cl/2015/10/29/sindicalismo-autonomo-sector-publico-en-alerta-ante-regulacion-del-gobierno/.

Ugarte, José (2016). Reforma Laboral: "El proyecto es un retroceso para el mundo sindical". Ciper. Recuperado de http://ciperchile.cl/2015/09/29/reforma-laboral-elproyecto-es-un-retrocesopara-el-mundo-sindical/ [25-02-2020].

Ulloa, Victor (2003). El movimiento sindical chileno del siglo XX hasta nuestros días. OIT, Oficina Internacional del Trabajo.

Urrutia, Miguel, Sebastián Osorio y Karim Campusano (2015). Nuevas formas y horizontes de politización sindical en el marco de conflictos laborales: Un estudio exploratorio en la Región Metropolitana, de Valparaíso y del Bío-Bío. CIPSTRA, FACSO.

Wada, Takeshi (2014). Who are the active and central actors in the 'rising civil society'in Mexico? Social Movement Studies, 13(1): 127-157.

Winn, Peter (2004). Victims of the Chilean Miracle: Workers and Neoliberalism in the Pinochet Era, 1973-2002. Duke University Press.

\section{Sobre el autor}

Rodrigo M. Medel es Sociólogo de la Universidad de Chile. Magíster en Sociología, Magíster en Ciencia Política y Doctor en Ciencia Política de la Pontificia Universidad Católica de Chile. Actualmente es investigador del Observatorio de Huelgas Laborales y académico del Departamento de Política y Gobierno de la Universidad Alberto Hurtado. Sus temas de interés son: estudios laborales, movimientos sociales, métodos de investigación y participación política. Correo Electrónico: rmedel@uahurtado. cl. (iD) https://orcid.org/0000-0002-6610-3809 


\title{
CUHSO
}

Fundada en 1984, la revista CUHSO es una de las publicaciones periódicas más antiguas en ciencias sociales y humanidades del sur de Chile. Con una periodicidad semestral, recibe todo el año trabajos inéditos de las distintas disciplinas de las ciencias sociales y las humanidades especializadas en el estudio y comprensión de la diversidad sociocultural, especialmente de las sociedades latinoamericanas y sus tensiones producto de la herencia colonial, la modernidad y la globalización. En este sentido, la revista valora tanto el rigor como la pluralidad teórica, epistemológica y metodológica de los trabajos.

\author{
EDITOR \\ Matthias Gloël \\ COORDINADORA EDITORIAL \\ Claudia Campos Letelier \\ CORRECTOR DE ESTILO Y DISEÑAdOR \\ Ediciones Silsag \\ TRADUCTOR, CORRECTOR LENGUA INGLESA \\ Aurora Sambolin Santiago \\ SITIO WEB \\ cuhso.uct.cl \\ E-MAIL \\ cuhso@uct.cl \\ LICENCIA DE ESTE ARTÍCULO \\ Creative Commons Atribución Compartir Igual 4.0 Internacional
}

